\section{Effects of high dose intravenous immunoglobulin in two severe corticosteroid insensitive asthmatic patients}

\author{
Bart Vrugt, Susan Wilson, \\ Edwin van Velzen, Aad Bron, \\ Janis K Shute, Stephen T Holgate, \\ Ratko Djukanovic, René Aalbers
}

\begin{abstract}
Preliminary observations of the clinical efficacy of intravenous immunoglobulin in two patients with severe corticosteroid insensitive asthma are reported. In both patients treatment with intravenous immunoglobulin resulted in clinical improvement and enabled a significant reduction in the dose of prednisolone. In one of the patients fibreoptic bronchoscopy with endobronchial biopsies was performed and peripheral blood was analysed by flow cytometry before and after treatment. Immunohistological analysis of the biopsy samples after treatment showed a decrease in the number of all cell types, especially CD3 $+\mathbf{T}$ cells, CD4 $+\mathbf{T}$ cells, and activated $\mathrm{CD} 25+\mathrm{T}$ lymphocytes, which was associated with a reduction in peripheral blood $T$ cell activation. Intravenous immunoglobulin may be a valid option for the treatment of corticosteroid insensitive asthma. To elucidate the role and mode of action of intravenous immunoglobulin further studies in larger groups of patients are needed.

(Thorax 1997;52:662-664)
\end{abstract}

Keywords: asthma, intravenous immunoglobulin.

The use of intravenous immunoglobulin (Ig) in the treatment of severe asthma was found to be beneficial in one open study of clinical efficacy. ${ }^{1}$ We treated two severe asthmatic patients who were found to be corticosteroid insensitive as judged by requirements of high doses of systemic corticosteroids, low prebronchodilator forced expiratory volume in one second $\left(\mathrm{FEV}_{1}\right)$ values $(<70 \%)$, and decreased sensitivity of peripheral blood mononuclear cells to the inhibitory effects of dexamethasone in vitro. ${ }^{2}$ In one of the patients we have de- termined the effects of intravenous immunoglobulin treatment on $\mathrm{T}$ lymphocyte and eosinophil numbers and their state of activation in endobronchial biopsy specimens and peripheral blood. In the same patient we have investigated the ability of intravenous immunoglobulin to modulate the concentration of interleukin 8 (IL-8) and its IgG autoantibodies in the circulation.

\section{Case reports}

CASE 1

A 15 year old girl with corticosteroid insensitive asthma was admitted to our hospital. On admission she was dyspnoeic at rest with a Cushingoid appearance. Lung function tests showed an obstructive pattern $\left(\mathrm{FEV}_{1} 57 \%\right.$, forced vital capacity (FVC) 80\%, airways resistance (Raw) $372 \%$ of predicted). Peak expiratory flow (PEF) variability was $65 \%$. Total IgE was 2280 IU/1 (normal <80 IU/1) with positive radio allergosorbent tests (RAST) for house dust mite and other aeroallergens.

Despite optimal treatment consisting of prednisolone $(60 \mathrm{mg} /$ day $)$, inhaled budesonide $(3000 \mu \mathrm{g} /$ day $)$, theophylline, and nebulised bronchodilators, her asthma proved difficult to control. Increasing the dose of oral prednisolone to $100 \mathrm{mg}$ daily led to a modest decrease in PEF variability to $40 \%$. Additional treatment with methotrexate did not result in clinical improvement or reduction of the dose of prednisolone, and was associated with considerable gastrointestinal side effects. After four weeks methotrexate was therefore discontinued (fig 1).

Treatment with intravenous immunoglobulin (Sandoglobulin, Sandoz, Bern, Switzerland) in a dosage of $84 \mathrm{~g}$ once a month (2 g/ $\mathrm{kg}$ body weight) was commenced five months after admission. After two months of treatment there was a clear clinical improvement associated with a reduction in PEF variability to $10 \%$, enabling the dose of prednisolone to be reduced to $10 \mathrm{mg} /$ day. Mean morning PEF increased from 160 to $320 \mathrm{l} / \mathrm{min}$, PEF variability decreased to $5 \%$, and $\mathrm{FEV}_{1}$ and FVC were $96 \%$ and $95 \%$ of predicted (fig 1 ).

CASE 2

The second patient, an 18 year old woman with a history of severe, poorly controlled asthma, was admitted to our institution in 1992 for evaluation and treatment. Since 1986 her asthma had been difficult to control with episodes of nocturnal symptoms and frequent emergency room visits. On admission we saw a dyspnoeic woman with Cushingoid features and $\mathrm{FEV}_{1}$ of $51 \%$ predicted. Treatment consisted of prednisolone $(30 \mathrm{mg} /$ day $)$, inhaled budesonide $(2400 \mu \mathrm{g} /$ day $)$, formoterol, and nebulised bronchodilators. Increasing the dose of prednisolone to $90 \mathrm{mg} /$ day did not lead to 


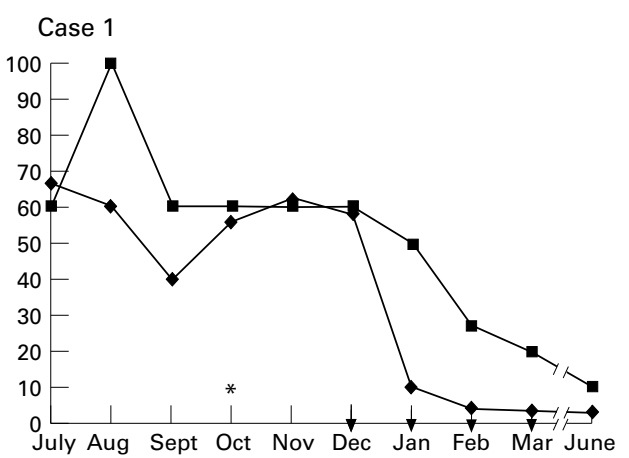

Case 2

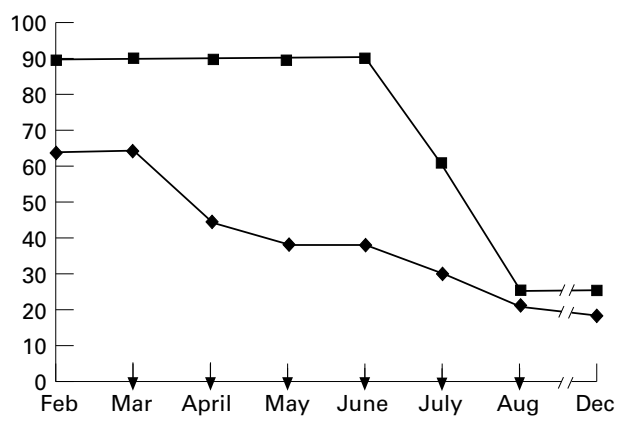

Figure 1 Decrease in PEF variability $(\diamond)$ and doses of prednisolone ( $\mathbf{\square}$ in the two patients following treatment with intravenous immunoglobulin ( $)$. In case $1 *$ marks the introduction of methotrexate (15 $\mathrm{mg} /$ week).

clinical improvement $\left(\mathrm{FEV}_{1} 58 \%\right.$ of predicted). In March 1993 intravenous immunoglobulin therapy ( $2 \mathrm{~g} / \mathrm{kg}$ body weight/month) was introduced. Fibreoptic bronchoscopy with endobronchial biopsy samples and flow cytometric analyses of peripheral blood were performed before and after four months of treatment. During the period of treatment with intra-

Table 1 Results of immunohistological analyses of bronchial biopsy specimens and flow cytometric analyses of peripheral blood before and after treatment with intravenous immunoglobulin in case 2

\begin{tabular}{|c|c|c|c|}
\hline & Before & After & $\%$ change \\
\hline \multicolumn{4}{|l|}{ Biopsy specimen* } \\
\hline Leucocytes (CD45) & 160 & 117 & -27 \\
\hline $\mathrm{T}$ cells $(\mathrm{CD} 3)$ & 116 & 84 & -28 \\
\hline $\mathrm{T}$ helper cells (CD4) & 58 & 26 & -55 \\
\hline $\mathrm{T}$ suppressor cells (CD8) & 25 & 20 & -20 \\
\hline Interleukin 2 receptor (CD25) & 30 & 14 & -53 \\
\hline Neutrophils (elastase) & 25 & 18 & -28 \\
\hline Mast cells (tryptase) & 18 & 15 & -17 \\
\hline Activated eosinophils (EG2) & 8 & 6 & -25 \\
\hline \multicolumn{4}{|l|}{ Blood } \\
\hline Leucocytes $\left(\times 10^{6} / \mathrm{ml}\right)$ & 5.6 & 5.6 & 0 \\
\hline \multicolumn{4}{|l|}{ Differential count } \\
\hline Neutrophils (\%) & 50 & 57 & 12 \\
\hline Basophils (\%) & 0 & 0 & 0 \\
\hline Eosinophils (\%) & 9 & 8 & -12 \\
\hline Monocytes (\%) & 8 & 6 & -25 \\
\hline Lymphocytes (\%) & 33 & 25 & -12 \\
\hline \multicolumn{4}{|l|}{ Flow cytometry of lymphocytes } \\
\hline CD $3(\%)$ & 80 & 69 & -14 \\
\hline CD4 (\%) & 39 & 36 & -8 \\
\hline $\mathrm{CD} 4 / \mathrm{CD} 25(\%) \dagger$ & 7.1 & 1 & -86 \\
\hline CD4/HLA-DR $(\%) \dagger$ & 5.9 & 1 & -83 \\
\hline CD8 (\%) & 32 & 25 & -22 \\
\hline CD8/CD25 (\%)† & 0.5 & 0 & -100 \\
\hline CD8/HLA-DR (\%)† & 13.9 & 1 & -92 \\
\hline CD19 (\%) & 3 & 7 & 133 \\
\hline CD19/CD23 (\%)† & 68 & 56 & -18 \\
\hline
\end{tabular}

* Number expressed as total cell count per $\mathrm{mm}^{2}$ submucosa located beneath the basement membrane.

† Percentages of $\mathrm{T}$ and B lymphocytes expressing activation markers CD25 (IL-2R), HLA-DR (MHC class II), and CD23 (low affinity IgE receptor) venous immunoglobulin her medication was kept constant including oral prednisolone $(90 \mathrm{mg} /$ day $)$ and inhaled budesonide $(2400 \mu \mathrm{g} /$ day). The mean asthma symptom score decreased from 8.9 to 5.1 . PEF variability improved from $64.1 \%$ to $37.7 \%$. Treatment with intravenous immunoglobulin was continued after the second bronchoscopy for a further two months during which oral prednisolone could be reduced from 90 to $25 \mathrm{mg}$ /day while PEF variability improved further to $15 \%$ (fig $1)$. This was accompanied by an increase in $\mathrm{FEV}_{1}$ from $68 \%$ of predicted before to $98 \%$ of predicted after six months of treatment. One year after intravenous immunoglobulin was introduced no exacerbations have occurred.

Immunohistological analysis of bronchial tissue after treatment with intravenous immunoglobulin revealed a decrease in the number of all cell types, especially CD $3+\mathrm{T}$ cells, $\mathrm{CD} 4+\mathrm{T}$ cells, and activated CD25 + T lymphocytes (table 1). Similarly, flow cytometric analysis of peripheral blood showed a decrease in $\mathrm{CD} 3+$ and $\mathrm{CD} 4+\mathrm{T}$ cells bearing IL-2R and HLA-DR as well as reduced percentage of activated CD23 + B cells (table 1 ). Total serum IgE was decreased by $51 \%$ (from 3320 to $1622 \mathrm{IU} / \mathrm{l}$ ) while IgG levels increased from 8.1 to $29.6 \mathrm{~g} / 1$ (normal range $8-17 \mathrm{~g} / \mathrm{l}$ ). Free IL-8 was reduced by $72 \%$ (from 0.232 to $0.064 \mathrm{ng} /$ $\mathrm{ml}$ ), together with a $178 \%$ increase in IL-8/ IgG complexes (from 0.061 to 0.170 units $/ \mathrm{ml}$ ) and a $28 \%$ increase in free $\mathrm{IgG}$ autoantibody (from 0.341 to 0.438 units $/ \mathrm{ml}$ ). Serum eosinophilic cationic protein (ECP), measured before and one week after the first infusion of intravenous immunoglobulin, showed a decrease from $34.6 \mu \mathrm{g} / 1$ (normal $<16.0 \mu \mathrm{g} / \mathrm{l}$ ) to undetectable levels and stayed undetectable throughout the remaining treatment period.

\section{Discussion}

In two patients with corticosteroid insensitive asthma treated with high doses of intravenous immunoglobulin we have observed a clear therapeutic benefit consisting of improved and long lasting control of asthma. This enabled a reduction in the dose of oral corticosteroids which in both patients was associated with significant morbidity. These observations are consistent with those of Mazer and Gelfand. ${ }^{1}$

In the second case the improvement in airway inflammation was associated with a reduction in markers of disease activity in peripheral blood. Among the immunomodulating capacities of intravenous immunoglobulin, its potential to suppress $T$ cell activation and $B$ cell differentiation into antibody-secreting cells is relevant to asthma. ${ }^{3}$ Although the knowledge about the composition of intravenous immunoglobulin is incomplete and hence the action of the individual components unclear, soluble CD4, CD8, and HLA molecules have recently been detected in commercially available immunoglobulin preparations. ${ }^{4}$ It is possible that intravenous immunoglobulin exerts a therapeutic effect via interaction between soluble CD4 and HLA class II molecules on antigen-presenting cells, resulting in non- 
specific immunosuppression with decreased expression of IL-2R on T cells and subsequently reduced secretion of cytokines such as IL-4 and IL-5.

There is growing evidence that IL- 8 plays an important role in the recruitment of inflammatory cells into the lungs of asthmatic subjects. $^{5}$ Intravenous immunoglobulin may contain autoantibodies against cytokines, such as anti-IL-8 autoantibody, which neutralise their biological effects. ${ }^{6}$ The reduction in free IL-8 appears to result from its binding with the blocking IgG anti-IL-8 antibody present in intravenous immunoglobulin, a hypothesis that is supported by the substantial increase in IL-8/IgG complexes after treatment.

To clarify the role and mode of action of intravenous immunoglobulin in the treatment of corticosteroid insensitive asthma, further studies in larger groups of patients are needed.

The authors would like to thank Sandoz Berne for the donation of intravenous immunoglobulins.

1 Mazer BD, Gelfand EW. An open-label study of high-dose intravenous immunoglobulin in severe childhood asthma. f Allergy Clin Immunol 1991;87:976-83.

2 Corrigan CJ, Brown PH, Barnes NC, Szefler SJ, Tsai J-J, Frew AJ, et al. Glucocorticoid resistance in chronic asthma. Glucocorticoid pharmacokinetics, glucoconticoid receptor characteristics, and inhibition of peripheral blood T to proliferation by glucocorticoids in vitro. Am Rev Respir Dis proliferation by glucoc

3 Hall PD. Immunomodulation with intravenous immunoglobulin. Pharmacotherapy 1993;13:564-73.

4 Blasczyk R, Westhoff U, Grosse-Wilde H. Soluble CD4 CD8, and HLA molecules in commercial immunoglobulin preparations. Lancet 1993;341:789-90.

5 Shute J. IL-8 is a potent eosinophil chemoattractant. Clin Exp Allergy 1994;24:203-6.

6 Sylvester I, Yoshimura T, Sticherling M, Schröder J-M, Ceska $M$, Peichl P, et al. Neutrophil attractant protein-1-immunoglobulin $\mathrm{G}$ immune complexes and free anti-NAP-1 antibody in normal human serum. F Clin Invest 1992;90: $471-81$ 